\title{
EFFECT OF CHEMICAL REACTION ON MHD FLOW OF A VISCO-ELASTIC (WALTER'S LIQUID MODEL-B) FLUID THROUGH POROUS MEDIUM WITH HEAT SOURCE
}

\author{
A.RUCHI CHATURVEDI, B.Dr.R.K.SHRIVATAV, C.Dr.MOHD. SALIM AHAMAD \\ A.FET-AGRA COLLEGE,AGRA, \\ ruchiaec3@gmail.com \\ B.HEAD AND PROFESSOR DEPARTMENT OF MATHEMATICS, AGRA COLLEGE, AGRA, \\ dr.srivastavark@yahoo.com \\ C.HINDUSTAN COLLEGE OF SCIENCE AND TECHNOLOGY, FARAH, MATHURA, \\ mohdsalim10@gmail.com
} ABSTRACT

In this paper we have studied and discussed the problem of unsteady flow of a visco-elastic (walter's liquid model B) fluid through porous medium in presence of a heat source and a uniform magnetic field with effect of chemical reaction parameter. The effect of chemical reaction parameter $\gamma$, porous parameter $\mathrm{K}$ and magnetic parameter on fluid velocity, temperature and concentration with respect to vertical axis $Y$ and time $t$ are discussed graphically.

Keywords: Chemical reaction, MHD, Visco-elastic, Walter's Liquid Model-B, Heat source, Porous medium, Unsteady.

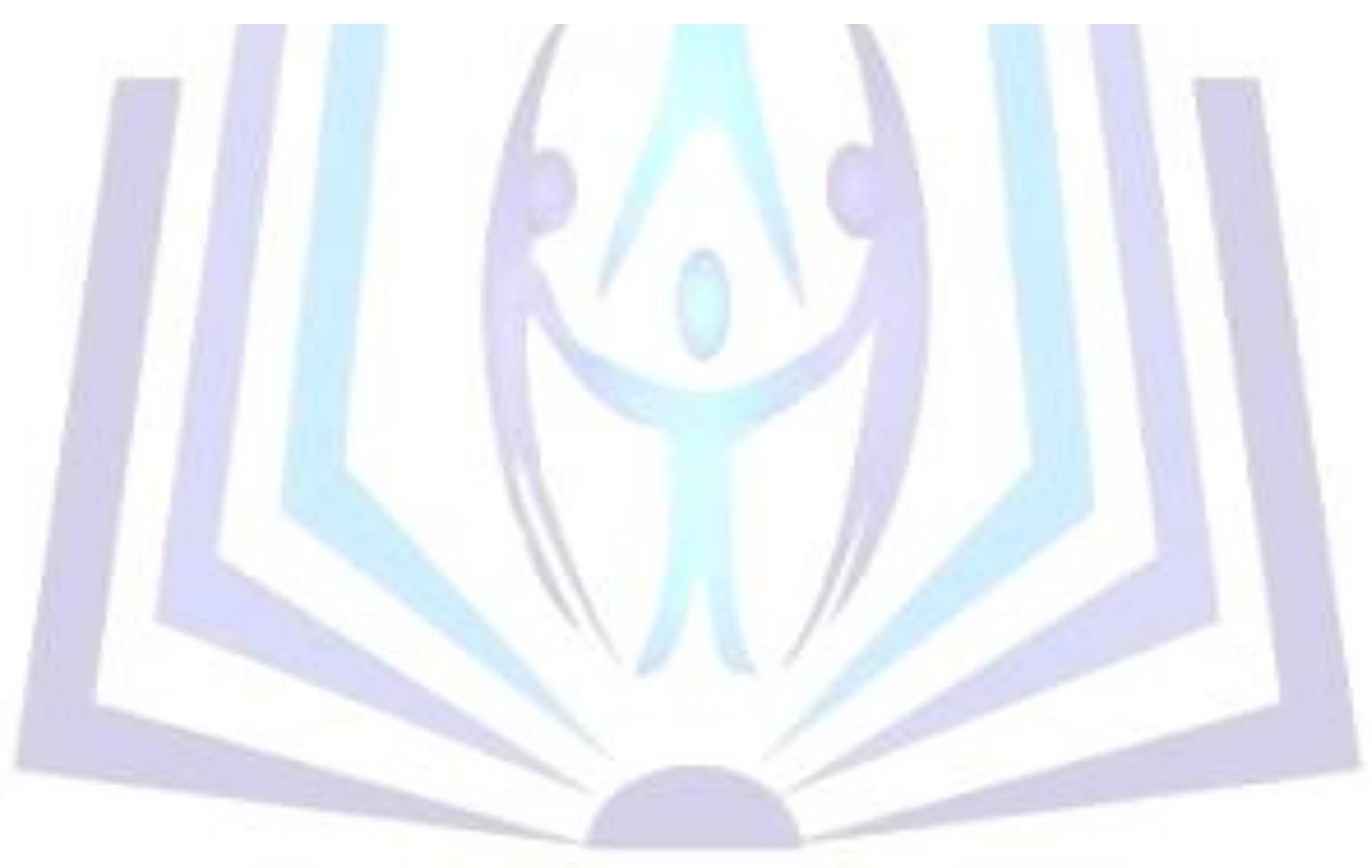

\section{Council for Innovative Research}

Peer Review Research Publishing System

Journal: INTERNATIONAL JOURNAL OF COMPUTERS \& TECHNOLOGY

Vol 8, No 1

editor@cirworld.com

www.cirworld.com, member.cirworld.com 


\section{INTRODUCTION:}

in view of heat and mass transfer and chemical reactions numerous and wide-ranging applications in various fields like polymer processing industry in particular in manufacturing process of artificial film and artificial fibers and in some applications of dilute polymer solution. Sakiadis [1,2] was the first study of boundary layer problem assuming velocity of a boundary sheet as constant. This work is followed by the pioneering work of Tsou et al. [3] studied the flow and heat transfer developed by continuously moving surface both analytically and experimentally, in which the flow is caused by an elastic sheet moving in its own plane with a velocity varying linearly with the distance from a fixed point studied by Chen [4]. There are several extensions to this problem, which include consideration of more general stretching velocity and the study of heat transfer [6-14].

In view of increasing importance of non-Newtonian flows, a great deal of work has been carried out to find the similarity solution of visco-elastic fluid flow over impervious stretching boundary. Rajagopal et al. [14] examined for a special class of visco-elastic fluids known as second order fluids. All these studies deals with the studies concerning non-Newtonian flows and heat transfer in the absence of magnetic fields, but present years we find several industrial applications such as polymer technology and metallurgy [17], where the magnetic field is applied in the visco-elastic fluid flow. Sarpakaya [18] was mostly first researcher to investigate MHD flows of non-Newtonian fluids [19-20] investigated the flow problem of electrically conducting visco-elastic fluid past a flat and impermeable elastic sheet.

Chemical reactions usually accompany a large amount of exothermic and endothermic reactions. These characteristics can be easily seen in a lot of industrial processes. Recently, it has been realized that it is not always permissible to neglect the convection effects in porous constructed chemical reactors [24]. The reaction produced in a porous medium was extraordinarily in common, such as the topic of PEM fuel cells modules and the polluted underground water because of discharging the toxic substance, etc.

Fourier's law, for instance, described the relation between energy flux and temperature gradient. In other aspects, Fick's law was determined by the correlation of mass flux and concentration gradient. Moreover, it was found that energy flux can also be generated by composition gradients, pressure gradients, or body forces. The energy flux caused by a composition gradient was discovered in 1873 by Dufour and was correspondingly referred to the Dufour effect. It was also called the diffusion-thermo effect. On the other hand, mass flux can also be created by a temperature gradient, as was established by Soret. This is the thermal-diffusion effect. In general, the thermal-diffusion and the diffusion-thermo effects were of a smaller order of magnitude than the effects described by Fourier's or Fick's law and were often neglected in heat and mass transfer processes. There were still some exceptional conditions. The thermal-diffusion effect has been utilized for isotope separation and in mixtures between gases with very light molecular weight $(\mathrm{H} 2, \mathrm{He})$ and of medium molecular weight (N2, air), the diffusion-thermo effect was found to be of a magnitude such that it may not be neglected in certain conditions [25]. In recent years, Kandasamy et al. studied the heat and mass transfer under a chemical reaction with a heat source [26,27]. Seddeek studied the thermal radiation and buoyancy effect on MHD free convection heat generation flow over an accelerating permeable surface with the influence temperature dependent viscosity [28], and later the chemical reaction, variable viscosity, radiation, variable suction on hydro magnetic convection flow problems were included [29-32].

The flow of an incompressible viscous fluid past an impulsively started infinite horizontal plate, in its own plane, was first studied by Stokes [35], It is also known as Rayleigh's problem in the literature. Following Stokes' analysis, Soundalgekar [33] first presented free convection effects on the Stokes problem for an infinite vertical plate. Soundalgekar [34] has studied mass transfer effects on flow past an impulsively started infinite vertical plate. The study of convection with heat and mass transfer is very useful in fields such as chemistry, agriculture and oceanography. A few representative fields of interest in which combined heart and mass transfer play an important role are the design of chemical processing equipment, formation and dispersion of fog, distribution of temperature and moisture over agricultural fields and groves of fruit trees, damage of crops due to freezing, and pollution of the environment. This technique is used in the cooling processes of plastic sheets, polymer fibers and glass materials and in drying processes of paper. Das et. al [5] considered the mass transfer effects on flow past an impulsively started infinite isothermal vertical plate with constant mass flux. Muthucumaraswamy, et. al. [17] have studied heat and mass transfer effects on flow past an impulsively started vertical plate. Kumar, P. and et. al. [36] have discussed MHD flow of a visco-elastic (Walter's liquid model-B) fluid through porous medium. Heat and mass transfer in MHD visco-elastic fluid flow through a porous medium over a stretching sheet under chemical reaction has been studied recently by Saleh M. Alharbi [37].

Recently Bhagwat Swarup and Kuldeep [38] have investigated the effect of heat source of unsteady flow of a visco-elastic (WALTER'S LIQUID MODEL-B) fluid through porous medium past an impulsively started vertical plate in presence of a uniform magnetic field. In this paper our aim to investigate and analyse the effect of chemical reaction on the flow of visco-elastic fluid (Walter's Model-B) through porous media.

\section{FORMULATION OF THE PROBLEM}

We have considered the fluid which is (i) unsteady visco-elastic (Walters's liquid model-B), (ii) incompressible, (iii) electrically conducting, (iv) fluid past an impulsively started infinite vertical plate through a porous medium with heat source under the action of a uniform magnetic field. The $x$ '-axis taken along the plate in the vertically upward direction, and the $y^{\prime}$-axis is taken normal to the plate. At time $t^{\prime} \leq 0$, the plate and fluid are at 
same temperature and concentration in al stationary condition. At time $t^{\prime}>0$, the plate is given an impulsive motion in the vertical direction with constant velocity $\mathrm{u} 0$, and at the plate constant heat and mass flux are imposed. Under the effect of chemical reaction the concentration equation is having a parameter KI. Past an impulsively started vertical plate in presence of uniform magnetic field. Then under Boussinesq's approximation, the unsteady flow past an infinite vertical plate is governed by following equations:

$$
\begin{aligned}
& \frac{\partial u^{\prime}}{\partial t^{\prime}}=g \beta\left(T^{\prime}-T_{\infty}^{\prime}\right)+g \beta^{*}\left(C^{\prime}-C_{\infty}^{\prime}\right)+v\left(I-E^{\prime} \frac{\partial}{\partial t^{\prime}}\right) \frac{\partial^{2} u^{\prime}}{\partial y^{\prime 2}}-\frac{\sigma B_{0}^{2}}{\rho} u^{\prime}-\frac{v}{K^{\prime}} u^{\prime} \\
& \frac{\partial u^{\prime}}{\partial t^{\prime}}=\frac{k}{\rho C p} \frac{\partial^{2} T^{\prime}}{\partial y^{\prime 2}}+S^{\prime}\left(T^{\prime}-T_{\infty}^{\prime}\right) \\
& \frac{\partial C^{\prime}}{\partial t^{\prime}}=D \frac{\partial^{2} C^{\prime}}{\partial y^{\prime 2}}-K_{r}\left(C^{l}-C_{\infty}^{l}\right)
\end{aligned}
$$

With following initial and boundary conditions :

$$
\left.\begin{array}{ll}
u^{\prime}=u_{0} \frac{\partial T^{\prime}}{\partial y^{\prime}}=-\frac{q}{k} \frac{\partial C^{\prime}}{\partial y^{\prime}}=-\frac{j^{\prime \prime}}{D} & \text { at } y^{\prime}=0, t^{\prime}=0 \\
u^{\prime}=u_{0} T^{\prime} \rightarrow T^{\prime} \quad C^{\prime} \rightarrow C_{\infty}^{\prime} & \text { at } y^{\prime}=0, t^{\prime}=0
\end{array}\right\}
$$

On introducing the following non-dimensional quantities:

$$
\begin{aligned}
& u=\frac{u^{\prime}}{u_{0}}, t=\frac{u_{0}^{2} t^{\prime}}{v}, y=\frac{y^{\prime} u_{0}}{v}, \theta=\frac{\left(T^{\prime}-T_{\infty}^{\prime}\right)}{\left(\frac{q v}{k u_{0}}\right)}, \varphi=\frac{\left(C^{\prime}-C_{\infty}^{\prime}\right)}{\left(\frac{j^{\prime \prime} v}{D u_{0}}\right)} \\
& G r=\frac{v g \beta\left(\frac{q v}{k u_{0}}\right)}{u_{0}^{3}}, \quad G c=\frac{v g \beta^{*}\left(\frac{j^{\prime \prime} v}{D u_{0}}\right)}{u_{0}^{3}}, \quad \operatorname{Pr}=\frac{\mu C p}{k} \\
& S c=\frac{v}{D}, \quad M=\frac{\sigma B_{0}^{2} v}{\rho u_{0}^{2}}, \quad K=\frac{K^{\prime} u_{0}^{2}}{v^{2}} \\
& E=\frac{E^{\prime} u_{0}^{2}}{v} \text { (visco-elastic parameter), } \\
& S=\frac{S^{\prime}}{v} \text { (heat source parameter) } \mathrm{u} \\
& K_{r}=\gamma \frac{u_{0}^{2}}{v} \quad \text { (Chemical Reaction Parameter) }
\end{aligned}
$$

Now, equations (1) to (3) in non-dimensional forms are

$$
\frac{\partial u}{\partial t}=G r \theta+G c \varphi+\left(1-E \frac{\partial}{\partial t}\right) \frac{\partial^{2} u}{\partial y^{2}}-\left(M+\frac{1}{K}\right) u
$$




$$
\begin{gathered}
\frac{\partial \theta}{\partial t}=\frac{1}{\operatorname{Pr}} \frac{\partial^{2} \theta}{\partial y^{2}}+S^{\prime}\left(T^{\prime}-T_{\infty}^{\prime}\right) \\
\frac{\partial \varphi}{\partial t}=\frac{1}{S c} \frac{\partial^{2} \varphi}{\partial y^{2}}-\gamma_{\varphi}
\end{gathered}
$$

The boundary condition (4) becomes:

$$
\begin{aligned}
& u=1, \quad \frac{\partial \theta}{\partial y}=-1, \quad \frac{\partial \phi}{\partial y}=-1 \quad \text { at } y=0, t=0 \\
& u=0, \quad \theta \rightarrow 0 \quad \varphi \rightarrow 0 \quad \text { as } y \rightarrow \infty
\end{aligned}
$$

We assume the following solutions :

$$
\left.\begin{array}{l}
u(y, t)=u_{0}(y) \cdot e^{-n t} \\
\theta(y, t)-\theta_{0}(y) \cdot e^{-n t} \\
\varphi(y, t)=\varphi_{0}(y) \cdot e^{-n t}
\end{array}\right\}
$$

Using (9) in (5) to (7), we find

$$
\begin{aligned}
& u_{0}^{\prime \prime}-(Q-n) A u_{0}=G r A_{1} \theta_{0}-G r A_{1} \varphi_{0} \\
& \theta_{0}^{\prime \prime}+(\operatorname{Pr} n+S) \theta_{0}=0 \\
& \phi_{0}^{\prime \prime}+S c(n-\gamma) \phi_{0}=0
\end{aligned}
$$

With corresponding boundary conditions:

$$
\begin{aligned}
& u=1, \quad \frac{\partial \theta}{\partial y}=-1, \quad \frac{\partial \phi}{\partial y}=-1 \quad \text { at } \quad y=0, t=0 \\
& u=0, \quad \theta \rightarrow 0 \quad \varphi \rightarrow 0 \quad \text { as } \quad y \rightarrow \infty
\end{aligned}
$$

Solving equations (10) to (12) under boundary condition (13), we get:

$$
\begin{aligned}
& u_{0}=e^{0 \sqrt{A_{2} y}}-G r A_{7} \sin A_{3} y-G c A_{8} \sin A_{4} y \\
& \theta_{0}=\frac{\sin A_{3} y}{A_{3}} \\
& \phi_{0}=\frac{\sin A_{4} y}{A_{4}}
\end{aligned}
$$

The real part of solutions: 


$$
\begin{aligned}
& u=\left(e^{-\sqrt{A_{2}} y}-G r A_{7} \sin A_{3} y-G c A_{8} \sin A_{4} y\right) e^{-n t} \\
& \theta=\left(\frac{\sin A_{3} y}{A_{3}}\right) e^{-n t} \\
& \phi=\left(\frac{\sin A_{4} y}{A_{4}}\right) e^{-n t}
\end{aligned}
$$

where

$$
\begin{aligned}
& Q=\left(M+\frac{1}{K}\right), \quad A_{1}=\frac{1}{(1+n E)}, \\
& A_{2}=A_{1}(Q-n), \quad A_{3}=\sqrt{\operatorname{Pr} . n+S} \\
& A_{4}=\sqrt{S c(n-\gamma)} \quad A_{5}=\frac{A_{1}}{A_{3}}, \quad A_{6}=\frac{A_{1}}{A_{4}} \\
& A_{7}=\frac{A_{5}}{A_{3}^{2}+A_{2}}, \quad A_{8}=\frac{A_{6}}{A_{4}^{2}+A_{2}} .
\end{aligned}
$$

3. RESULTS AND DISCUSSION:

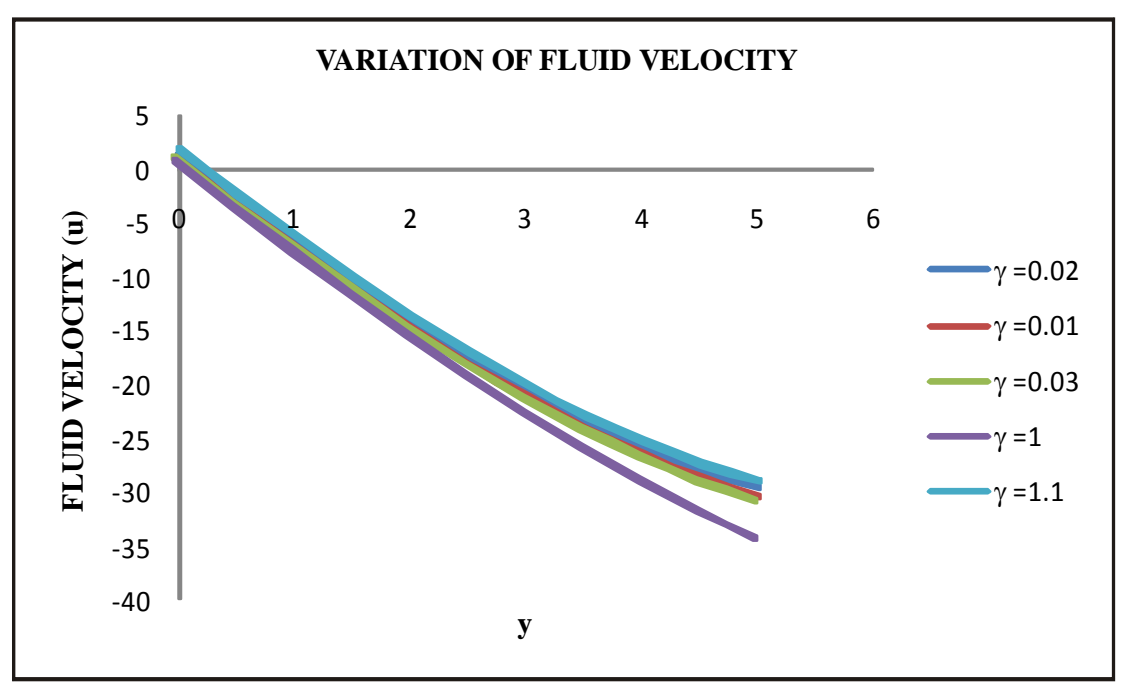

Fig.-1:Figure is drawn in between y and fluid velocity $u$ for the different values of chemical reaction parameter $\gamma$. This shows that as we increase $\gamma$ fluid velocity slightly increases. initially it is approx same. 


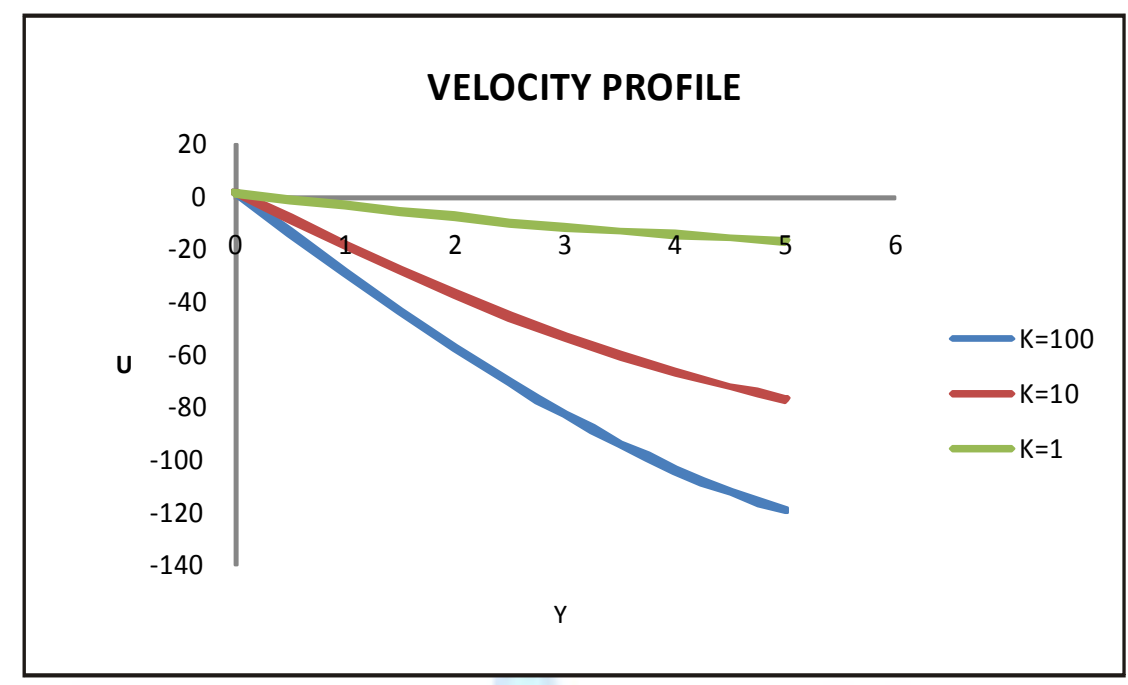

Fig.-2:Figure is drawn in between $y$ and fluid velocity $u$ for the different values of porous parameter $\mathrm{K}$. This shows that as we increase $\mathrm{K}$ fluid velocity decreases significantly.

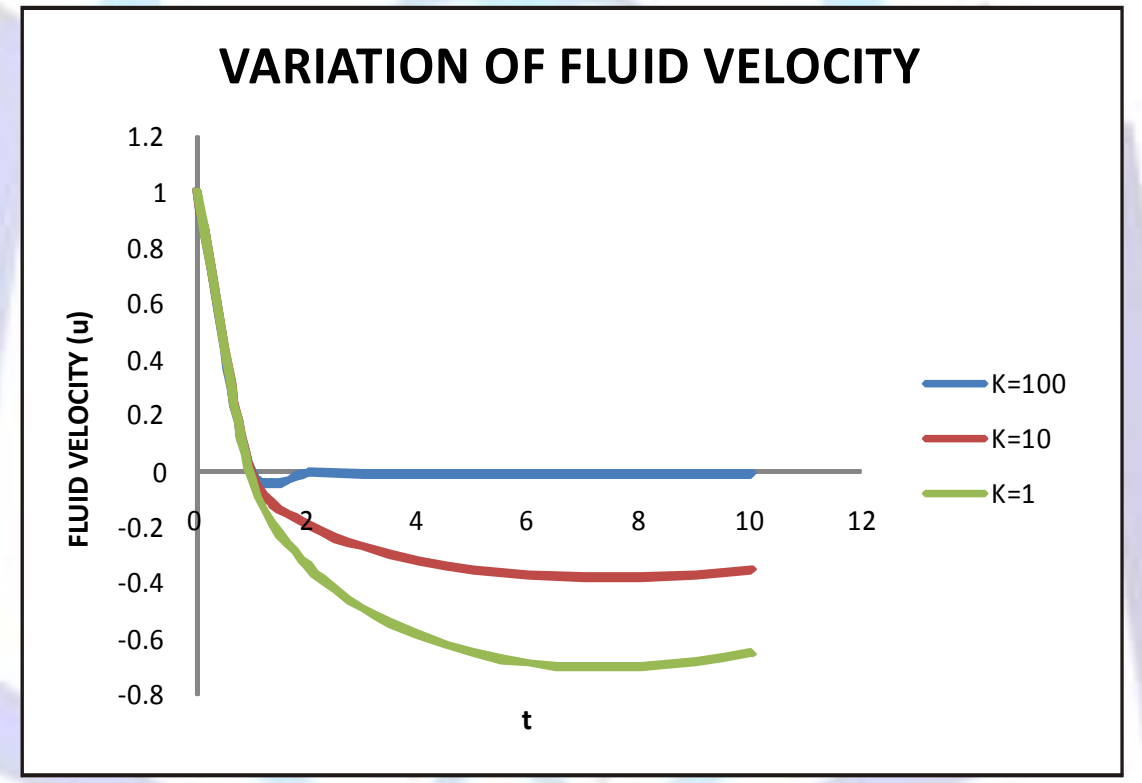

Fig.-3: Figure is drawn in between time $t$ and $u$ for the different values of porous parameter $\mathrm{K}$. initially no change but after reaching a constant value it increases significantly.

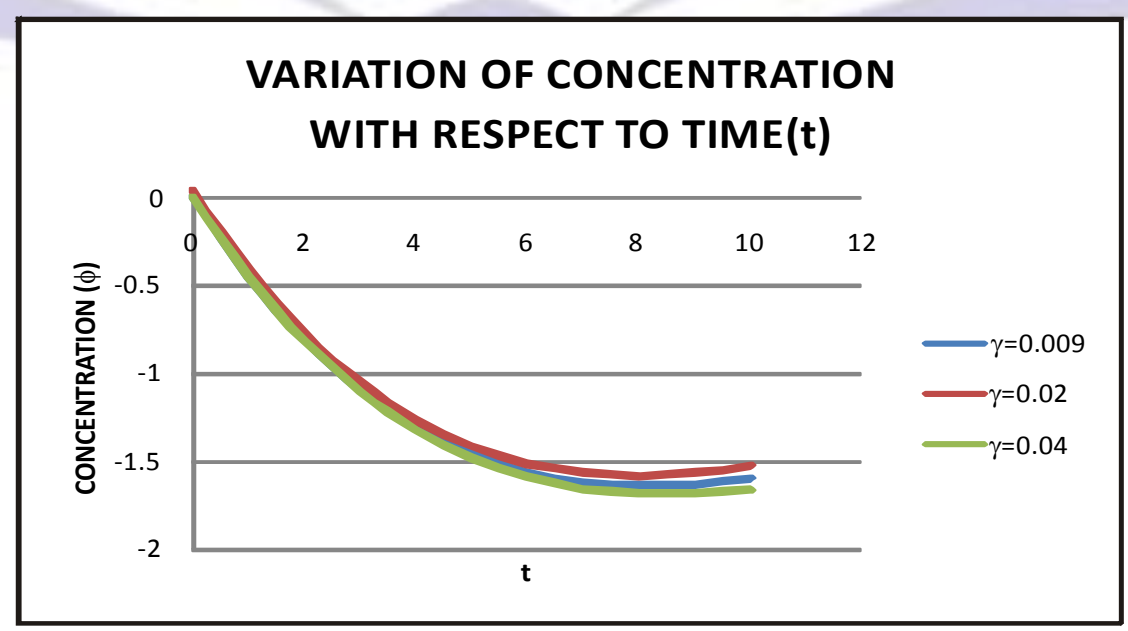

Fig.-4: Figure is drawn between $\phi$ and time $t$ for different values of $\gamma$ as we increase $\gamma, \phi$ slightly increases. 


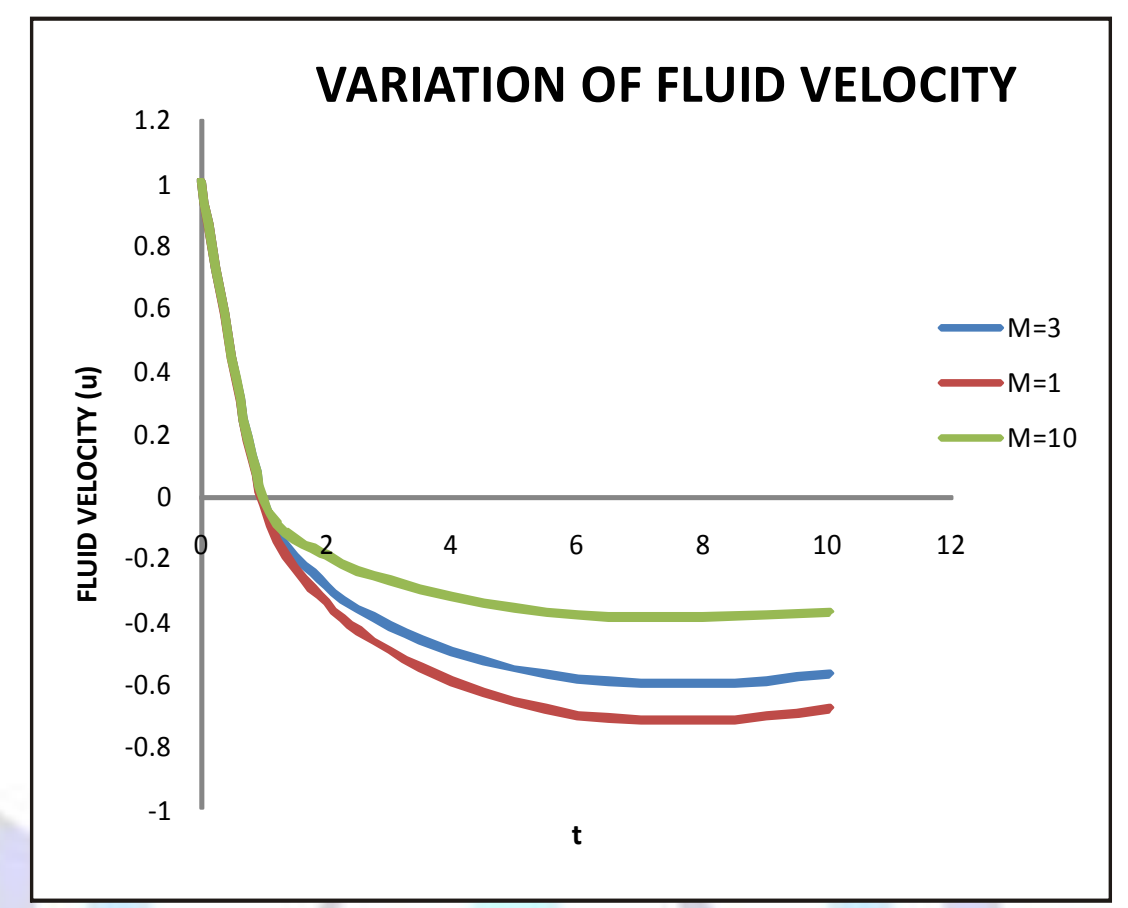

Fig.-5: Figure is drawn in between time $t$ and fluid velocity u for the different values of magnetic parameter $M$. We observed that as we increase $M, u$ increases in the same ratio.

\section{CONCLUSION}

The velocity profiles for the fluid and concentration drawn in fig. 1, 2, 3, 4 \& 5 taking $S=0.02, S c=0.4$, $\operatorname{Pr}=0.71, \mathrm{Gr}=2$ and $\mathrm{Gc}=3$. The results obtained here shows that if we increase chemical reaction parameter a slight but effective change in fluid velocity appears, which is increasing in nature we also observe that fluid velocity decreases significantly with increase in porous parameter $\mathrm{K}$ with respect to $\mathrm{y}$ but fluid velocity increases for the different values of porous parameter with respect to time. We also observe which we have not shown by graph that no effect of porous parameter $\mathrm{K}$, chemical reaction parameter $\gamma$ and magnetic parameter $\mathrm{M}$ on temperature. It is also seen that as we increase chemical reaction parameter a slight but effective increase and concentration is found. No effect of porous parameter $\mathrm{K}$ and $\mathrm{M}$ on concentration $\phi$.

5. APPENDIX

\subsection{NOMENCLATURE}

$\begin{array}{lll}\text { Sc } & - & \text { Schemidt Number } \\ \mathrm{M} & - & \text { Hartman Number } \\ \mathrm{K} & - & \text { Porous Parameter } \\ \mathrm{E} & - & \text { Viso-elastic Parameter } \\ \mathrm{S} & - & \text { Heat Source Parameter } \\ \mathrm{Kr} & - & \text { Chemical Reaction Parameter } \\ \mathrm{U} & - & \text { Fluid Velocity } \\ \theta & - & \text { Temperature of the fluid } \\ \phi & - & \text { Concentration of the fluid }\end{array}$




\subsection{REFERENCE:}

1. B. C. Sakiadis, "Boundary Layer Behavior on Continuous Solid Surfaces: I. Boundary Layer Equations for Two Dimensional and Axisymmetric Flow," AICHE Journal, Vol. 7, No. 1, March 1961, pp. 26-28.

2. B. C. Sakiadis, "Boundary Layer Behavior on Continuous Solid Surfaces: II. Boundary Layer on a Continuous Flat Surface," AICHE Journal, Vol. 7, 1961, pp. 221-225.

3. F. K. Tsou, E. M. Sparrow and R. J. Goldstein, "Flow and Heat Transfer in the Boundary Layer on a Continuous Moving Surface," International Journal of Heat and Mass Transfer, Vol. 10, 1967, pp. 219-223.

4. C. K. Chen and M. I. Char, "Heat Transfer of a Continuous Stretching Surface with Suction or Blowing," Journal of Mathematical Analysis and Applications, Vol. 135, No. 2, November 1988, pp. 568-580.

5. Das, U.N., Ray, S.N. and Soundalgekar, V.M., Mass transfer effects on flow past an impulsively started infinite vertical plate with constant mass flux and exact solution. Heat and Mass Transfer, 31, 163-167 (1996).

6. T. C. Chiam, "Heat Transfer in a Variable Conductivity in a Stagnation Point Flow towards a Stretching Sheet," International Communications in Heat and Mass Transfer, Vol. 23, No. 2, March-April 1996, pp. 239-248.

7. E. M. Abo Eldahab and M. S.El Gendy, "Radiation Effect on Convective Heat Transfer in an Electrically Conducting Fluid at a Stretching surface with Variable Viscosity and Uniform Free-Stream," Physica Scripta, Vol. 62, No. 4, 2000, pp. 321-325.

8. E. M. Abo Eldahab and M. S. El Gendy, "Convective Heat Transfer past a Continuously Moving Plate Embedded in a Non-Darcian Porous Medium in the Presence of a Magnetic Field," Canadian Journal of Physics, Vol. 79, 2001, pp. 1031-1038.

9. A. Megahed, S. R. Komy and A. A. Afify, "Similarity Analysis in Magneto hydrodynamics Hall Effect on Free Convection Flow and Mass Transfer past Semi Infinite Vertical Flat Plate," International Journal of Non-Linear Mechanics, Vol. 38, 2003, pp. 513-520.

10. M. A. Seddeek, "Effects of Non-Darcian on Forced Convection Heat Transfer over a Flat Plate in a Porous Medium- with Temperature Dependent Viscosity," International Communications in Heat and Mass Transfer, Vol. 32, 2005, pp. 258-265.

11. M. A. Seddeek and M. S. Abdelmeguid, "Effects of Radiation and Thermal Diffusivity on Heat Transfer over a Stretching Surface with Variable Heat Flux," Physics Letters A, Vol. 348, No. 3-6, January 2006, pp. 172-179.

12. A. Afify, "Similarity Solution in MHD: Effects of Thermal Diffusion and Diffusion Thermo on Free Convective Heat and Mass Transfer over a Stretching Surface Considering Suction or Injection," Communications in Nonlinear Science and Numerical Simulation, Vol. 14, No. 5, May 2009, pp. 2202-2214

13. M. A. Seddeek, S. N. Odda and M. S. Abdelmeguid, "Numerical Study for the Effects of Thermophoresis and Variable Thermal Conductivity on Heat and Mass Transfer over an Accelerating Surface with Heat Source," Computational Materials Science, Vol. 47, No. 1, 2009, pp. 93-98.

14. K. R. Rajagopal, T. Y. Na and A. S. Gupta, "Flow of Visco-Elastic Fluid over a Stretching Sheet," Rheol Acta, Vol. 23, 1984, pp. 213-215.

15. Chakrabarti and A. S. Gupta, "Hydromagnetic Flow and Heat Transfer over a Stretching Sheet," Quarterly Journal of Mechanics and Applied Mathematics, Vol. 37, 1979, pp. 73-78.

16. Gebhart, B. and Pera, L., The nature of vertical natural convection flows resulting from the combined buoyancy effects of thermal and mass transfer and mass diffusion. Int. J. Heat Mass Transfer, 14, 2025-2050 (1971).

17. Muthucumaraswamy, R., Genesan, P. and Soundalgekar, V.M., Heat and Mass transfer effects on flow past an impulsively started vertical plate. Acta Mech., 146, 1-8 (2001).

18. T. Sarpakaya, "Flow of Non-Newtonian Fluids in Magnetic Field," AICHE Journal, Vol. 7, 1961, pp. 324-328. [20] H. I. Andersson, "MHD Flow of Visco-elastic Fluid past a Stretching Surface," Acta Mechanica, Vol. 95, 1992, pp. 227- 230.

19. S. Abel, A. Joshi and R. M. Sonth, "Heat Transfer in a MHD Visco-Elastic Fluid over a Stretching Surface," Journal of Applied Mathematics and Mechanics, Vol. 81, 2001, pp. 691-698.

20. S. Abel, P. H. Veena, K. Rajgopal and V. K. Pravin, "Non-Newtonian Magneto Hydrodynamic Flow over a Stretching Surface with Heat and Mass Transfer," International Journal of Non-Linear Mechanics, Vol. 39, 2004, pp. 1067-1078. 
21. M. A. Seddeek, "Heat and Mass Transfer on a Stretching Sheet with a Magnetic Field in a Visco-Elastic Fluid Flow through a Porous Medium with Heat Source or Sink," Computational Materials Science, Vol. 38, 2007, pp. 781-787.

22. S. Abel and N. Mahesha, "Heat Transfer in MHD Visco-elastic Fluid Flow over a Stretching Sheet with Variable Thermal Conductivity, Non-Uniform Heat Source and Radiation," Applied Mathematical Modelling, Vol. 32, 2008, pp. 1965-1983.

23. K. V. Prasad, D. Pal, V. Umesh and N. S. Prasanna Rao, "The Effect of Variable Viscosity on MHD Visco-elastic Fluid Flow and Heat Transfer over a Stretching Sheet," Communications in Nonlinear Science and Numerical Simulation, Vol. 15, No. 2, February 2010, pp. 331-344.

24. D. A. Nield and A. Bejan, "Convection in Porous Media," 2nd Edition, Springer-Verlag, New York, 1999.

25. E. R. G. Eckert and R. M. Drake, "Analysis of Heat and Mass Transfer," McGraw-Hill, New York, 1972.

26. R. Kandasamy, K. Periasamy and K. K. Sivagnana Prabhu, "Chemical Reaction, Heat and Mass Transfer on MHD Flow over a Vertical Stretching Surface with Heat Source and Thermal Stratification Effects," International Journal of Heat and Mass Transfer, Vol. 48, No. 21-22, October 2005, pp. 4557- 4561.

27. R. Kandasamy, K. Periasamy and K. K. S. Prabhu, "Effect of Chemical Reaction, Heat and Mass Transfer along a Wedge with Heat Source and Concentration in the Presence of Suction or Injection," International Journal of Heat and Mass Transfer, Vol. 48, No. 7, March 2005, pp. 1388-1394.

28. M. A. Seddeek, "Thermal Radiation and Buoyancy Effects on MHD Free Convection Heat Generation Flow over an Accelerating Permeable Surface with Temperature Dependent Viscosity," Canadian Journal of Physics, Vol. 79, 2001, pp. 725-732.

29. M. A. Seddeek, A. A. Darwish and M. S. Abdelmeguid, "Effect of Chemical Reaction and Variable Viscosity on Hydromagnetic Mixed Convection Heat and Mass Transfer for Hiemenz Flow through Porous Media with Radiation," Communications in Nonlinear Science and Numerical Simulation, Vol. 12, No. 2, March 2007, pp. 195-213.

30. M. A. Seddeek and A. M. Salem, "The Effect of an Axial Magnetic Field on The Flow and Heat Transfer about a Fluid Underlying the Axisymmetric Spreading Surface with Temperature Dependent Viscosity and Thermal Diffusivity," Computional Mechanics, Vol. 39, No. 4, 2007, pp. 401-408.

31. M. A. Seddeek, F. A. Salama, "The Effects of Temperature Dependent Viscosity and Thermal Conductivity on Unsteady MHD Convective Heat Transfer Past a Semi-Infinite Vertical Porous Moving Plate with Variable Suction," Computational Materials Science, Vol. 40, No. 2, August 2007, pp. 186-192.

32. T. Y. Na, "Computational Methods in Engineering Boundary Value Problems," Academic Press, New York, 1979.

33. Soundalgekar, V.M., Free convection effects on the Stokes problem for an infinite vertical plate. Trans. ASME. J. Heat Transfer, Vol. 99, p. 499-501 (1977).

34. Soundalgekar, V.M., Effects of mass transfer and free convection on the flow pastan impulsively started vertical plate. ASMEJ. Appl. Mech., 46, 757-760 (1979).

35. Stokes, G.G., On the effects of the internal friction of fluids on the motion of pendulums. Camber. Phil. IX, 8-106 (1851).

36. Kumar, P., Jha, R. and Singh, U.R., MHD flow of a visco-elastic (Walter's liquid model-B) fluid through porous medium. Acta Ciencia Indica, Vol. XXXIV M, No. 2, 759-764 (2008).

37. Bhagwat Swarup and Kuldeep, MHD flow of a visco-elastic (Walter's liquid model-B) fluid through porous medium. Acta Ciencia Indica, Vol. XXXV M, No. 2, 605-610 (2010). 